\title{
LANGUAGE LEARNING STRATEGIES USED BY IRAQI PRIMARY SCHOOL CHILDREN
}

\author{
Muna Mohammed Abbas Alkhateeb ${ }^{1^{*}}$, Hasanein Hasan ${ }^{2}$ \\ ${ }^{1}$ Dr., Faculty of Basic Education, Babylon University, IRAQ, muna alkhteeb2003@yahoo.com; \\ munaalkhteeb2003@gmail.com \\ ${ }^{2}$ Mr., Faculty of Basic Education, Babylon University, IRAQ, hasaneinhs@yahoo.com \\ ${ }^{*}$ Corresponding author
}

\begin{abstract}
Since the amount of information to be processed by language learners is high in language classroom, learners use different language learning strategies in performing the tasks and processing the new input they face. This paper presented the learning strategies used by Fifth and Sixth primary graders in government schools in Babylon in Iraq. The Strategy Inventory for Language Learning questionnaire has been conducted with a sample of 120 pupils to identify the strategies used during language learning. Children were included in this part of the study in an attempt to understand how children engage with and acquire the English language which is a foreign language to them and not easily heard around them. The focus here is to document the strategies that children use in their learning and working with an unfamiliar language. Interesting result of the investigation in this study is that, despite their age and very brief exposure to English, these young learners reported using many learning strategies to assist their second language learning. There is also evidence from this study that children of this age can describe their strategies effectively. Findings also provided strong evidence that all learners, irrespective of their stage or their proficiency, have an extensive resort to learning strategies which they are used in the process of acquiring a particular area of the $\mathrm{FL}$ as a reflection of the learning patterns adopted during the language learning process. The results of the study indicated that differences in strategies used by young learners were found in the group preference of strategy categories in both grades.
\end{abstract}

Keywords: SILL, Oxford's classification, metacognitive strategies, Iraqi primary schools, Critical Period Hypothesis, Language Learning strategies.

\section{LANGUAGE LEARNING STRATEGIES: A BACKGROUND}

The interest in language learning strategies can be traced back to two different movements: the "good language learner' in America (Rubin, 1975; Stern, 1975; Naiman et al., 1978) and 'autonomous language learning' in Europe (Abe et al., 1975; Stanchina, 1976). In the early 1970s, the Council of Europe pushed countries to substitute their structural, grammar-based curriculum with a notional and functional syllabus. With this new type of curriculum came a shift from teacher-centred instruction towards more learner-centred, 
interactive and communicative teaching. The pursuit of learner autonomy (Holec, 1981,1988; Dam, 1995) required a focus on strategic thinking. Many researchers focus on how learners process new information and what kinds of strategies they use to understand, learn or remember the information in the area of second or foreign language learning. For a long time, researches were trapped in the belief that imitation and repetition are evident characteristics of learning (Brooks and Brooks, 1999), but these proved to be undesirable techniques in modern language classes for their neglect of the role of intellect, i.e. the making of a language response is not much of a step towards learning (Chomsky, 1975).

Language learning strategies have been defined as specific actions, behaviour patterns or techniques undertaken by learners to enhance their own learning (Scarcella \& Oxford, 1992: 63). In Oxford's words (1990: 8) "Learning strategies are operations employed by the learner to aid the learning, storage, retrieval, and use of information. [.... They] make learning easier, faster, more enjoyable, more self-directed, more efficient and more transferable to new situations.

All the researches recognized lists of learning strategies that applied to successful ESL/EFL learners. As indicated, there are many language learning strategies which have been studied and classified in various ways by many researchers since the 1970s. Naiman et al. (1978:13-15) summarizes the main language learning strategies classification within five categories: Active task approach, Realization of Language as a System, Realization of Language as a means of communication and interaction, Management of active demands, and Monitoring of L2 performance. Naiman et al. claims that language learners recognize language as a means of communication and interaction, and in the early stages, they tend to emphasize fluency over accuracy, and seek out opportunities to interact with members of the target language community and to improve their communication skills. In addition, these researchers noted that language learners are able to manage the affective demands of learning a new language by striving to overcome their inhibitions and to laugh at their own mistakes. language learners also monitor their second language performance by testing their guesses, looking for positive and negative evidence as they compare their speech to that of target language speakers, and by trying to emulate the speech of native speakers . Rubin's (1981:124-125) then presents strategies under two headings: Under the first heading are strategies that directly affecting learning which includes the following strategies: Clarification/Verification' (asking for a correct form, asking if a rule fits a particular case, or if a given form is explained by a previously learned rule, and looking up a structure in a grammar book); 'Monitoring' (self-correction and noting source of errors, observing others' language use for comparison);Memorization (the learner uses various techniques to memorize lists of words, idiomatic expressions grammar rules and so on; Guessing/inductive inferencing can be defined as goal-directed actions allows for a clearer understanding of strategies. They can be a sign that students make a deliberate effort to find the meaning of unknown words. However, it can also reveal superficial reading. In the first case, the goal is to improve language competence, in the second, to avoid active engagement in language learning ;Production tricks 'Deductive Reasoning' (rule search, use and adjustment, including drawing on cross-linguistic comparisons); and 'Practice' which includes 'consciously applying grammatical rules when speaking' and practicing corrected forms and then extending them to other contexts. While under the processes that contribute indirectly to learning, the strategy through which opportunities are created to learners to practice the language.

Brown and Palinscar (1982) and O'Malley et al (1985) present another classification of learning strategies: Metacognitive strategies: managing or regulating one's own efforts in the learning process. Those strategies involve thinking about the learning process, planning for learning, monitoring of comprehension and production while it is taking place, and self evaluation after the learning has been completed; Cognitive strategies: related to cognitive processing, such as inferencing, guessing and relating new information to old, etc.; Socio-affective strategies: how to interact with other learners and manage one's feelings in the learning process. This category only has three items such as asking for clarification, the redirecting of negative thoughts about the one's capability to perform a task with assurances that the task performance is within reach.

In 1990, Oxford synthesizes language leaning strategies which were divided into two categories: direct strategies and indirect strategies which help students to learn a target language. Oxford's (1990) classification of language learning strategies is more comprehensive and detailed and she had made a change just with the Getting help strategy as she shifted it from the indirect strategy 'Social strategy' to be one of the 'compensation' strategies in her the very recent classification. Direct strategies fall into three main groups: memory strategies, cognitive strategies and compensation strategies. Indirect strategies are further subdivided into three groups: metacognitive strategies, affective strategies and social strategies. These categories were devised for a classroom setting. 


\section{THE IMPORTANCE OF LANGAUGE LEARNING STRATEGIES}

According to Fedderholdt (1997:1), the language learner capable of using a wide variety of language learning strategies appropriately can improve his language skills in a better way. Metacognitive strategies improve organization of learning time, self-monitoring, and self-evaluation. Cognitive strategies include using previous knowledge to help solve new problems. Social and affective strategies include asking native speakers to correct their pronunciation, or asking a classmate to work together on a particular language problem. Developing skills in three areas, such as metacognitive, cognitive, and social and affective can help the language learner build up learner independence and autonomy whereby he can take control of his own learning. Lessard-Clouston (1997:3) states that language learning strategies contribute to the development of the communicative competence of the students. Being a broad concept, language learning strategies are used to refer to all strategies foreign language learners use in learning the target language and communication strategies are one type of language learning strategies. It follows from this that language teachers aiming at developing the communicative competence of the students and language learning should be familiar with language learning strategies. As Oxford (1990:1) states, language learning strategies "... are especially important for language learning because they are tools for active, self-directed movement, which is essential for developing communicative competence". Therefore, when language learners encounter language learning tasks such as reading or writing, they can apply the several different strategies to complete the tasks. Language learners will be successful in the tasks due to use of an appropriate language learning strategy (Richard, 1994). Oxford (1990: 9) claims that language learning strategies have the following features as shown in Fig. 1

\begin{tabular}{|ll|}
\hline Language Learning Strategies \\
\hline 1. & Contribute to the main goal, communicative competence \\
2. & Allow learners to become more self- directed \\
3. & Expend the role of teachers \\
4. & Are problem-oriented \\
5. & Are specific actions taken by the learners \\
6. & Involve many aspects of the learners, not just the cognitive \\
7. & Support learning both directly and indirectly \\
8. & Are not always observable \\
9. & Are often conscious \\
10. & Can be taught \\
11. & Are flexible \\
12. & Are influenced by a variety of factors \\
\hline
\end{tabular}

Figure 1: Features of Language Learning Strategies: Oxford (1990)

Research into the language learning strategies revealed a number of positive strategies so that such strategies could also be used by bad language learners trying to become more successful in language learning. However, there is always the possibility that bad language learners can also use the same language learning strategies while becoming unsuccessful owing to some other reasons. At this point, it should be strongly stressed that using the same language learning strategies does not guarantee that bad learners will also become successful in language learning since other factors may also play role in success.

\section{METHODOLOGY}

\subsection{The Sample}

The sample used was 120 students of fifth and sixth grades in two governmental schools in Al-Hilla city in Babylon Governorate. The population consisted of 60 male pupils (comprising 30 pupils from fifth grade 30 from sixth grade) from AL-Fatimia primary school for boys and 60 female students (compromising 30 pupils from fifth grade 30 from sixth grade) from Bint AL-Huda primary school for girls. Ages ranged from 10-12 years old and there were an approximately equal number of males and females about $50 \%$ for each. The majority of the subjects had had little or no previous second language learning experience (except for the 
hours of English they have taken in their schools). The Grades 5 and 6 levels are particularly well suited to the survey designed here since most of the pupils at those grade levels have had to develop their skills in English as the reading and writing skills are included in those two grade levels. If they had developed any strategies in learning their foreign language, these would be manifested at those last two levels point.

\subsection{Children's Questionnaire}

The strategy assessment tool used was an adaptation of the Strategy Inventory for Language Learning (SILL) (Oxford, 1990)(See the Appendix). The SILL is a structured 5-point scale questionnaire based on the following responses to each strategy item: never or almost never true of me, generally not true of me, somewhat true of me, generally true of me and always or almost always true of me (Oxford \& Burry-Stock, 1995). This tool is a self-scoring, paper-and-pencil survey. The original version of the SILL (5.1 Version for English Speakers Learning a New Language) was an 80 -item questionnaire. This version was adapted by Oxford to produce a 50- item questionnaire, the SILL 7.0 (Version for Speakers of Other Languages Learning English). The SILL contains the following six broad strategy categories: Memory, Cognitive, Compensation, Metacognitive, Affective, and Social. The items contained therein are self-explanatory. The SILL has been the principal instrument in more than forty studies, including twelve dissertations and theses which have involved approximately 8000-8500 language learners. Before the final set of items was selected, each item in the LLS was analyzed by re-reading the description of the strategy to which it referred in Oxford's seminal book on this issue (Oxford, 1990). The criteria used in making the questionnaire originally designed for adults appropriate for use with children were simplicity, comprehensibility to children, random selection among various strategy items which could be considered redundant, taking into account those items that were perhaps the most clearly expressed.

After its translation into Arabic, the researcher made copies of the questionnaire and submitted them to five juries from the Faculty of Education at Babylon and Al-Anbar Universities for validation (Oxford \& BurryStock, 1995). Students were asked to respond on the Arabic version using the following five-point scale: 1) Never, 2) Rarely, 3) Sometimes, 4) Usually, 5) Always.

\section{THE RESULTS}

\subsection{Direct Language Learning Strategies}

All direct strategies require mental processing of the language, but the three groups of direct strategies (memory, cognitive, and compensation) do this processing differently and for different purposes.

-The first category is the Memory Strategies, called mnemonics which help learners link one L2 item or concept with another but do not necessarily involve deep understanding. (See Oxford, 1990 for details). This category reported to be used by almost $74 \%$ of these children in both grades. The results signifying that both male and female subjects, regardless of their proficiency, showed a similar pattern of use of the individual items within the memory category. But a difference can be seen between grades as the results showed that $79 \%$ of Fifth grade reported using memory strategies, whereas Sixth grade with $68 \%$. Results indicated that using mechanical techniques, associating, reviewing, and using imagery were significantly more frequently used than the rest of memory strategies. The probable reason for this is that memory strategies are often used for memorizing vocabulary and structures in initial stages of language learning, but that learners need such strategies much less when their arsenal of vocabulary and structures has become larger.

- The second category that is Cognitive strategies, which enable the learner to manipulate the language material in direct ways, e.g., through repetition, finding opportunities to practice English, recombining, reasoning, note-taking, summarizing, synthesizing, outlining, translating, transferring, practicing in naturalistic settings and practicing structures and sounds formally. Cognitive strategies were significantly related to L2 learning in studies by Kato (1996), Ku (1995), Oxford and Ehrman (1995), Oxford, Judd, and Giesen (1998), and Park (1994), among others. Of these studies, four were specifically in EFL settings: Ku (Taiwan), Oxford, Judd, and Giesen (Turkey), Park (Korea), Khaldi (Algeria).

The results revealed that more than half of the subjects in both grades $71 \%$ reported using cognitive strategies. We found a difference only between grades as the results showed that nearly $73.5 \%$ of Fifth grade reported using cognitive strategies, whereas $67.5 \%$ of Sixth grade. To find out which of these items were reported by the subjects to be used more frequently than others, the analysis of the results showed that Repetition, Practicing naturalistically, Practicing structures and sounds formally (Practice sounds), were more frequently used than other cognitive strategies .Results signifying that both male and female subjects, regardless of their proficiency, showed a very minute difference of use of the individual items within the Cognitive category. 
-The Compensation Strategies enable learners to use the new language either for comprehension or production despite limitations in knowledge. The Compensation strategy category was composed of the individual strategy items: Guessing, coining words, paraphrasing, using gestures or pause words, switching to the mother tongue, getting help, using a circumlocution which all help the learner make up for missing knowledge.

The outcome of compensation strategies reported to be the least used by children. The results revealed that only $60 \%$ in both grades reported using these strategies with $63.5 \%$ of Fifth grade and $56 \%$ of Sixth grade who reported employing these strategies in their Language learning. The results also revealed that there was a minute difference among groups particularly with Fifth grade females as $68 \%$ used those strategies more than other groups. An analysis of the respondents' scores on the Compensation category signifying that both male and female subjects, regardless of their proficiency, showed a similar pattern of use of the individual items within the compensation category, i.e., they reported that guessing ,and getting help were reported to be significantly more frequently used than using gestures and the rest of compensation strategies. The learners used guessing to help them when experiencing a temporary breakdown in speaking and writing performance. The pervious studies concluded that less proficient language learners need these compensatory production strategies even more, because they run into knowledge roadblocks more often than do individuals who are skilled in the language.

\subsection{Indirect Language Learning Strategies}

Indirect Strategies support and manage language learning without (in many instances) directly involving with the target language. Indirect strategies are useful in virtually all language learning situations and are applicable to all four language skills: listening, reading, speaking and writing. Those strategies are divided into metcognitive, affective and social.

-The fourth category that is Metacognitive Strategies. They are actions which go beyond purely cognitive devices. Ten strategies exist (e.g., identifying one's own learning style preferences and needs, paying attention, planning for an L2 task, gathering and organizing materials, Seeking opportunities, arranging a study space and a schedule, monitoring mistakes, and evaluating task success and the success of any type of learning strategy) all of which are employed for managing the learning process overall. Studies of EFL learners in various countries (e.g., in South Africa, Dreyer \& Oxford, 1996; and in Turkey, Oxford, Judd, \& Giesen, 1998), uncovered evidence that metacognitive strategies are often strong predictors of L2 learning.

Because the subjects reported most frequent use of the metacognitive strategy category, this category was further analyzed in order to find out which of the individual strategy items comprising this category were favoured by the children. The results showed $77 \%$ of all groups in both grades reported using metacognitive strategies. There was a difference, as the results revealed, when almost of Fifth grade females $83 \%$ reported using these strategies more than the rest groups i.e., $74 \%$ of Fifth grade male, $72 \%$ of Sixth grade female and $77 \%$ of Sixth grade male respectively. To find out which of metacognitive items were reported by the subjects to be used more frequently than others, the analysis of the results showed that male and female subjects, in both grades differ significantly in their use of the individual items Self-evaluating and monitoring, paying attention, and planning which were used more frequently by Sixth grade pupils than Fifth grade. The least reported strategy by all subjects in both grades was seeking practice opportunities. If we want to compare the results with other studies of second and foreign language learning such as ( O'Malley et al,1985 and Chamot et al, 1987), students used metacognitive strategies less often than cognitive strategies and were limited in their range of metacognitive strategies with planning most frequently employed and with little self-evaluation or self-monitoring.

- Affective Strategies refer to emotions, attitudes, motivations, and values. Such strategies include ten strategies in all (e.g., identifying one's mood and anxiety level (Relaxation), taking risks wisely, talking about feelings, using music and laughter rewarding oneself for good performance, listing to oneself body, writing diaries, using checklist and using deep breathing or positive self talk) have been shown to be significantly related to L2 learning proficiency .

Since the affective strategies was one of the least frequently used in the reports of the groups, and since proficiency differences also emerged on this category. The results obtained were very revealing as nearly $65 \%$ of all groups in Fifth and Sixth grades demonstrated that they used affective strategies. There was a significant difference between grades as the results showed that $73 \%$ of Fifth grade reported using affective strategies whereas $56.5 \%$ of Sixth grade. The outcomes also revealed differences between both groups of Sixth grade as females reported using affective strategies with $63 \%$ whereas the use of male group was $51 \%$. The subjects' responses on this category were further analyzed in order to find out which of the individual items comprising this category were used more frequently by the children. The analysis of the 
results showed that male and female subjects, in both grades did not differ significantly in their use of the individual items: Taking risks, relaxation, and self rewarding. Few studies have examined the frequency used of affective strategies, but those which have done so reveal that they are useful for the vast majority of language learners who have ordinary hang-ups or difficulties. Over time there might be less need for affective strategies as learner's progress to higher levels in learning.

-Finally, for the sixth and the last category, the Social Strategies, (e.g., asking questions to get verification, asking for clarification of a confusing point, asking for correction cooperating with peers in doing a language task, and exploring cultural and social norms) help the learner work with others and understand the target culture as well as the language.

The Social strategies were also reported to be among infrequently used strategies. An analysis of the respondents' scores on this category showed that $66 \%$ of the pupils in both grades reported using those strategies. The results showed a significant difference between both grades as $73 \%$ of Fifth grade reported using the social strategies while $59 \%$ of Sixth grade. In order to find out, when the social category was used, which items were used more frequently than others, the analysis of the respondents' responses signifying that both male and female pupils, regardless of their proficiency, showed a similar pattern of use of the individual items within the Social category: Asking for clarification and asking for correction were significantly more frequently used than the rest of social strategies. Many studies in the field of language learning demonstrated the utility of asking for clarification or verification and asking for correction strategies as they help learners to get closer to the intended meaning and thus aid their understanding.

\section{DISCUSSION}

Table 1 : Total score of Learning Strategies of Fifth and Sixth Pupils

\begin{tabular}{|l|c|}
\hline \multicolumn{1}{|c|}{ Categories } & Percentage \\
\hline Metacognitive Strategies & 77 \\
\hline Memory Strategies & 74 \\
\hline Cognitive Strategies & 71 \\
\hline Social Strategies & 66 \\
\hline Affective Strategies & 65 \\
\hline Compensation Strategies & 60 \\
\hline
\end{tabular}

The result of the above table shows that Fifth and Sixth grades pupils' responses on the strategies factor showed that the learners, in general, claimed more frequent use of the indirect learning strategies, metacognitive strategy category $77 \%$ more than the direct learning strategies, memory strategy $(74 \%)$. The memory strategy category, in turn, was reported to be used more than the cognitive strategy category $(71 \%)$. The cognitive strategy category was reported to be used more than the social strategy category $(66 \%)$. Then, the affective strategy category with $65 \%$. The compensation strategies category was the least to be used by $60 \%$ in both grades. To sum up, among the six categories of strategies used, the following pattern emerged: Metacognitive> Memory $>$ Cognitive > Social, Affective, and Compensation.

The results of fifth and sixth grades pupils indicated that the more frequent learning strategies used were the Metacognitive strategies and among the different items of the Metacognitive category, Self-evaluating and monitoring were the most frequently reported by the children. This was followed by paying attention, and planning. Seeking practice opportunities was the least frequently reported. Second, the next most frequently used category was the Memory category. Within this category, learners seemed to use the mechanical techniques, associating, reviewing, and using imagery items significantly more frequently than the other items. The Cognitive strategy category was the third choice in order of preference by the children. Of the individual items that make up the Cognitive category, the most frequently used were Repetition, Practicing naturalistically, Practicing structures and sounds formally. Questions were asked, under different categories, to determine the Children's use of naturalistic practice. In each case, except for watching television, the items involving naturalistic practice were not chosen by a great many of these learners. These findings that learners do not generally take advantage of the available opportunities for naturalistic practice reiterate the observation of Green and Oxford (1995), who found that in Puerto Rico, where the availability of opportunities for naturalistic practice is abundant, some learners do not take advantage of them. The results also indicated that there were differences in metacognitive, and compensation strategies between fifth Grade 
male and female pupils although female pupils were slightly more frequent users of these strategies than male pupils and there were no differences in the use of memory, cognitive, social, affective strategies between male and female pupils although female pupils were frequent users of these strategies than male pupils. This may be due to cultural reasons, motivation and learning styles. The sixth Grade results showed that there were differences in affective and social strategies between sixth Grade male and female pupils although female pupils were more frequent users of memory, cognitive, metacognitive, and social strategies than male pupils. The findings of this study were consistent with some studies like (Green, 1992; Noguchi, 1991; Green and Oxford, 1995; Oxford, 1992) whose results have favored females as more frequent users of strategies. Hsun (2002) found that females reported the use of language learning strategies more frequently than males. And this may be attributed to cultural background differences, age differences, and motivation differences.

Interesting result of the investigation in this part of the study is that, despite their age and very brief exposure to English, these young learners reported using many learning strategies to assist in their foreign language learning. There is also evidence from this study that children of this age can describe their strategies effectively. From the results, in the acquisition of the language, we can see that in the Fifth grade reported using Memory strategies more than Sixth grade. We think that this preference towards one strategy over another can be explained in terms of the different approaches learners adopted towards the acquisition of the language. Thus, Fifth grade pupils still rely heavily on their memory in learning the new points of the target language, a strategy which, as our investigation of their background has shown, they used quite often in the previous two years, whereas Sixth grade pupils showed that the way they learn the English language and its different areas by expanding the rules, structures, and new vocabularies they meet through the use of reference various materials.

As it has been referred to that Metacognitive strategies involve exercising "executive control" over one's language learning through planning, monitoring and evaluating. They are techniques that are used for organizing, planning, focusing and evaluating ones' learning. In general, these strategies help learners to gain control over their emotions and motivations related to language learning through self-monitoring. The high usage of metacognitive strategies among pupils is similar to that noticed among Indian students who seemed to favor functional practice strategies and other studies from Asian countries like Japan, China, Korea and Taiwan as reported in some of the Asia studies (e.g. Sheorey, 1998; Oxford et.al, 1991). Deoring (2000) also found that students used metacognitive strategies more than any other strategies. The use of some individual strategies may be attributed to cultural differences, students' personalities, task demands, age, and nature of the task and to the educational system in Iraq where pupils have very limited opportunities to use functional practice strategies. Moreover, pupils whether in grade Five or Six are more concerned in passing exams and responding to questions that are directly related to the content in their prescribed textbooks, in addition to the fact that rote memorizing is highly used by students who learn the language as isolated fragments.

\section{CONCLUSION}

We can say that our findings concerning the learning strategies have now provided us with enough evidence to confirm the occurrence of different learning strategies. Instead, some strategies tend to be more closely associated with the acquisition of a particular skill or language item rather than with another which itself, will tend to be more closely associated with other strategies. This does not imply however that the learning process should be seen as compartmentalized, i.e. that a giving group of learning strategies can only occur with a particular area of language acquisition, instead all the strategies we have discussed so far, may occur everywhere in the process of acquiring any of the areas of the foreign language. Our most important finding however is that the learning strategies used in the process of acquiring a particular area of the FL can be seen as a reflection of the learning patterns the learners adopt during the language learning process.

\section{REFERENCE LIST}

\section{Journals}

Cameron, L. (2001). Teaching Languages to Young Learners. Cambridge: Cambridge University Press.

Chamot, A. \& O'Malley, J. (1987) The Cognitive Academic Language Learning Approach: A bridge to the mainstream. TESOL Quarterly, 21 (2), 227-249. 
Green J. \& Oxford, R. (1995). A closer look at learning strategies, L2 proficiency, and gender. TESOL Quarterly. 29(2), 261-297.

Lessard-Clouston, M. (1997). Language Learning Strategies: An Overview for L2 Teachers. Internet TESL Journal

O’Malley, J., Chamot, A ., Stewner-Manzanares,G. , Kupper, L. \& Russo, R. (1985) Learning strategies used by beginning and intermediate ESL students. Language Learning, 35 (1), 21-46. - Oxford, R.L., \& Ehrman, M.E., (1995): Adults' language learning strategies in an intensive foreign language programme in the United States. System_, 23, 359-386.

Rubin, J. (1975) “What the 'good language learner' can teach us”. TESOL Quarterly, 9, p. 41-51.

Rubin, J. (1981).Learner strategies; theoretical assumptions, Research History and Typology. Englewood Cliffs, NJ: Prentice Hall.

-Stern, H. (1975) "What can we learn from the Good Language Learner?" Canadian Modem Language Review, 31, p. 304-318.

Zhao, A. \& Morgan, C. (2004). "Consideration of age in L2 attainment- children, adolescents and adults". Asian EFL Journal, 6(4).

\section{Books}

Chomsky, N. (1975) . Reflections on Language. New York ,Pantheon Books

Hughes, A. (2001). The teaching of language to young learners: linking understanding and principles with practice. In M. Raya, Faber, P., Gewehr, W., Peck, A. (Eds.), Effective Foreign Language Teaching at the Primary Level. - Focus on the Teacher (Vol. 4). Frankfurt am Main: Peter Lang.

Lenneberg, E. (1967). Biological Foundations of Language. London: Wiley.

Lightbown, P. \& Spada, N. (2006). How languages are learned ( $3^{\text {rd }}$ Ed. ). Oxford: Oxford University Press.

Naiman, N., Frohilich, M., Stern, H., and Todesco, A. (1978). The Good Language Learner. Toronto,Ontario: Ontario Institute for Studies in Education.

Oxford, R. (1990) Language Learning strategies, What every Teacher should know.Boston, Massachusetts: Heinle \& Heinle Publishers.

Oxford, R. L. \& Burry, S. J.(1995). Assessing the use of language learning strategies worldwide with the ESL/EFL. Version of the strategy inventory for language learning (SILL). University of Alabama, Tuscaloosa, AL, U. S.A.

Vale, D. \& Feunteun, A. (1995). Teaching Children English. - a Training Course for Teachers of English to Children. Cambridge: Cambridge University Press.

\section{Internet References}

Fedderholdt, K. (1997). Using Diaries to Develop Language Learning Strategies. Available at http://ialtpublications.org/ old tlt/files/98/apr/ fedderholdt.html 